\title{
Specification of Somatosensory Area Identity in Cortical Explants
}

\author{
Yorick Gitton, ${ }^{1}$ Michel Cohen-Tannoudji, ${ }^{2}$ and Marion Wassef ${ }^{1}$ \\ ${ }^{1}$ Centre National de la Recherche Scientifique Unité Mixte de Recherche 8542, Régionalisation Nerveuse, niveau 8, Ecole \\ Normale Supérieure, 75230 Paris Cedex 05, France, and 2Unité de Biologie du Développement, Centre National de la \\ Recherche Scientifique Unité de Recherche Associée 1960, Institut Pasteur, 75724 Paris, Cedex 15, France
}

The $\mathrm{H}-2 \mathrm{Z1}$ transgene is restricted to a subset of layer IV neurons in the postnatal mouse cortex and delineates exactly the somatosensory area. Expression of the $\mathrm{H}-2 \mathrm{Z} 1$ transgene was used as an areal marker to determine when the parietal cortex becomes committed to a somatosensory identity. We have shown previously that grafts dissected from embryonic day 13.5 (E13.5) H-2Z1 cortex and transplanted into the cortex of nontransgenic newborns express $\mathrm{H}-2 \mathrm{Z} 1$ according to their site of origin. Expression was not modified on heterotopic transplantation (Cohen-Tannoudji et al., 1994). In the present study, whole cortical explants were isolated at E12.5 from noncortical tissues. The explants developed a regionalized expression of $\mathrm{H}-2 \mathrm{Z1}$, indicating that regionalization takes place and is maintained in vitro. We used this property and confronted embryonic $\mathrm{H}-2 \mathrm{Z1}$ cortex with presumptive embryonic sources of regional- izing signals in an in vitro grafting procedure. A great majority of E11.5-E13.5 grafts maintained their presumptive expression of $\mathrm{H}-2 \mathrm{Z} 1$ when grafted heterotopically on nontransgenic E13.5E15.5 explants. However, a significantly lower proportion of E11.5 parietal grafts expressed $\mathrm{H}-2 \mathrm{Z1}$ in occipital compared with parietal cortex, indicating that somatosensory identity may be partially plastic at E11.5. Earlier stages could not be tested because the E10.5 grafts failed to develop in vitro. The data suggest that commitment to the expression of a somatosensory area-specific marker coincides with the onset of neurogenesis and occurs well before the birth of the non-GABAergic neurons that express $\mathrm{H}-2 \mathrm{Z} 1$ in vivo.

Key words: mouse somatosensory cortex; cortical area specification; explant culture; transplantation; $\mathrm{H}-2 \mathrm{Z1}$ transgene; cortical layer IV neurons
The mammalian neocortex is subdivided into functionally specialized areas that are anatomically distinguishable based on differences in cytoarchitecture and connections. Experimental manipulations and molecular approaches have provided evidence that areal identity is a set of properties that are progressively acquired during development. Expression of region-specific molecular markers has been found, in general, to be determined early in cortical development (Barbe and Levitt, 1991; Arimatsu et al., 1992; Cohen-Tannoudji et al., 1994; Ferri and Levitt, 1995; Nothias et al., 1998) together with proliferation characteristics (Dehay et al., 1993; Polleux et al., 1997), whereas connectional and cytoarchitectural features appear late (Stanfield et al., 1982) and are readily modified by experimental manipulations affecting afferent input (Van der Loos and Woolsey, 1973; Dawson and Killakey, 1987; O'Leary and Stanfield, 1989; Rakic et al., 1991; Schlaggar and O'Leary, 1991) or by mutations modifying the cross talk between thalamic afferents and their cortical targets (Schlaggar et al., 1993; Cases et al., 1995, 1996; Fox et al., 1996; Abdel-Majid et al., 1998).

The somatosensory cortex contains a topographically organized representation of sensory receptors that are present on the

\footnotetext{
Received Dec. 23, 1998; revised March 19, 1999; accepted March 23, 1999.

This work was supported by grants from the European Community (ERB BIO 4CT960146) and Human Frontier Science Program (RG83/96) to M.W. We acknowledge the skillful technical assistance of Rosette Goïame and the help of Jean-Marc Doisne. We thank A. Tobin for the gift of GAD 67 cDNA, A. Frankfurter for TuJ-1 antibody, and P. Daubas and C. Métin for critical reading of this manuscript.

Correspondence should be addressed to Marion Wassef, Régionalisation Nerveuse, Centre National de la Recherche Scientifique Unité Mixte de Recherche 8542, niveau 8, Ecole Normale Supérieure, 46, rue d'Ulm, 75230 Paris Cedex 05, France.

Copyright (C) 1999 Society for Neuroscience $\quad 0270-6474 / 99 / 194889-10 \$ 05.00 / 0$
}

body surface. In mice, the somatosensory cortex layer IV neurons form discrete aggregates around bundles of thalamic axons arranged in a somatotopic pattern (Woolsey and Van der Loos, 1970). The body map can be directly visualized with routine neuroanatomical procedures. Several molecules expressed in forebrain subregions (Levitt, 1984; Arimatsu et al., 1992; for review, see Levitt et al., 1997) that cross the cytoarchitectonic boundaries have been described in the developing cerebral cortex, yet $\mathrm{H}-2 \mathrm{Z} 1$ is the only area-specific marker described to date. $\mathrm{H}-2 \mathrm{Z} 1$ is an enhancer trap transgenic mouse line in which the lacZ reporter is specifically expressed in the somatosensory cortex where it is restricted to a subset of layer IV neurons (CohenTannoudji et al., 1992, 1994).

In a previous study, we found that fragments of embryonic day 13.5 (E13.5) H-2Z1 cortex maintain their presumptive expression of lacZ when grafted heterotopically into the cortex of newborn hosts (Cohen-Tannoudji et al., 1994). This indicated that information necessary for the adequate expression of a somatosensory-specific marker is already regionalized in the E13.5 mouse cortex and not drastically modified on heterotopic transplantation in a newborn cortex. Several questions about the specification of the somatosensory area raised by these observations remained unanswered. They concern three main issues. First, are H-2Z1-expressing cells directly involved in the formation or function of the somatosensory area, or is the specific expression of $\mathrm{H}-2 \mathrm{Z1}$ a marker or a consequence of somatosensory area determination? Second, how does the actual somatosensory cortex primordium relate to the broad regionalization demonstrated by transplantation experiments, and is the somatosensory area precisely delimited from early stages? Third, how does the chronology of specification of a marker of "somatosensory iden- 
tity" compare with that of the limbic cortex marker LAMP (Barbe and Levitt, 1991); does it remain plastic and is it influenced by interactions with neighboring regions of the cortical or striatal anlagen?

In the present study we tried to characterize the cortical cells that express the H-2Z1 transgene by examining their morphology and immunocytochemical characteristics. We then examined the early phases of specification of $\mathrm{H}-2 \mathrm{Z} 1$ expression using in vitro explants of developing telencephalic vesicles.

\section{MATERIALS AND METHODS}

Animals. H-2Z 1 (Cohen-Tannoudji et al., 1992) and $\beta$-geo ROSA-26 (Friedrich and Soriano, 1991) (purchased from Jackson Laboratories, Bar Harbor, ME) transgenic embryos were recovered from crosses between heterozygous $\mathrm{H}-2 \mathrm{Z} 1$ transgenic males and $(\mathrm{C} 57 \mathrm{BL} 6 / \mathrm{j} \times \mathrm{CBA}) \mathrm{F} 1$ females (Iffa Credo, Lyon, France) and ROSA-26 homozygous males and OF-1 females (Iffa Credo), respectively. OF-1 embryos were also used. The day of vaginal plug detection was considered E0.5. Parturition generally occurred late on E18.5; therefore, E18.5 or E19.5 were considered postnatal day $0(\mathrm{P} 0)$. All postnatal animals were anesthetized irreversibly with an overdose of ether or chloroform before any further processing, perfusion, or dissection. Embryos were recovered in chilled PBS and killed by decapitation or fixation.

Fixation. For histochemistry or immunocytochemistry, postnatal mice were perfused through the ascending aorta with a fixative containing either $4 \%$ paraformaldehyde or $2 \%$ paraformaldehyde $-0.2 \%$ glutaraldehyde in $0.12 \mathrm{M}$ phosphate buffer, $\mathrm{pH}$ 7.2-7.4. Perfusion lasted $10-15 \mathrm{~min}$, and the total fixation time varied between 15 and $30 \mathrm{~min}$. Embryos were fixed by immersion.

$\beta$-galactosidase histochemistry. Fixed postnatal brains were soaked for $2 \mathrm{~d}$ in $30 \%$ sucrose in PBS and $25-\mu$ m-thick sections were cut on a freezing microtome and processed freely floating. Alternatively, the fixed telencephalon was dissected out and embedded in gelatin/albumin $(30 \%$ albumin, $0.5 \%$ gelatin, in phosphate buffer $0.1 \mathrm{M}, \mathrm{pH} 7,3$ hardened by adding $1.25 \%$ glutaraldehyde). Transverse sections, $200 \mu \mathrm{m}$ thick, were cut on a vibrating slicer (Campden Instruments). Sections were washed in PBS $+0.1 \%$ Triton $\mathrm{X}-100$ (PBT). They were reacted overnight at $30^{\circ} \mathrm{C}$ in PBT containing $2 \mathrm{mM} \mathrm{MgCl}_{2}, 4 \mathrm{~mm} \mathrm{~K}_{4} \mathrm{Fe}(\mathrm{CN})_{6}, 4 \mathrm{~mm} \mathrm{~K}_{3} \mathrm{Fe}(\mathrm{CN})_{6}, 4$ $\mathrm{mg} / \mathrm{ml}$ of 4-chloro-5-bromo-3-indoyl- $\beta$-D-galactopyranoside (X-gal), and rinsed in PBT. A procedure was used before DiI tracing except that the brains were reacted in toto and Triton X-100 was omitted from the reaction mixture and from all rinses.

A diffusible $\beta$-galactosidase substrate [fluorescein di galactoside (FDG), Molecular Probes, Eugene, OR] was also used to outline the $\mathrm{H}-2 \mathrm{Z} 1$-expressing cells. The unfixed brains of 3-week-old $\mathrm{H}-2 \mathrm{Z} 1$ mice were dissected out in PBSG $\left[\mathrm{Ca}^{2+}, \mathrm{Mg}^{2+}\right.$-free PBS containing $33 \mathrm{~mm}$ glucose and $50 \mu \mathrm{g} / \mathrm{ml}$ penicillin-streptomycin (Life Technologies)] and embedded in agarose type VII (Sigma, St.Louis, MO; 3\% in PBSG). Sections (400 $\mu \mathrm{m}$ thick) were cut with a vibrating slicer and collected in L15 medium (Life Technologies, Gaithersburg,MD). Individual sections were placed on a glass slide in a drop of L15 medium. A drop of FDG (1:100 dilution in water of a $12.5 \%$ stock solution of FDG in $1: 1$ $\mathrm{DMSO} / \mathrm{H}_{2} \mathrm{O}$ ) was then added, and the section was immediately observed under fluorescein optics and photographed.

Immunocytochemistry. Frozen sections reacted for $\beta$-galactosidase activity were rinsed and processed for calbindin (1:2000), calretinin (1: 500 ), or parvalbumin (1:1000), all from Swant (Bellinzonia, Switzerland), and cow glial fibrillary acidic protein (GFAP; 1:1000 Dako, Denmark) immunochemistry. E10.5 and E11.5 brains were carefully dissected and used as whole mounts. Endogenous peroxidase activity was blocked by an overnight incubation in $0.2 \% \mathrm{H}_{2} \mathrm{O}_{2}$ at $4^{\circ} \mathrm{C}$ and processed for the detection of the same calcium-binding proteins and Tuj-1 (1:500; gift of A. Frankfurter). Biotinylated anti-rabbit or anti-mouse IgG was used as a secondary antibody (1:200, Jackson Laboratories) followed by streptavidinbiotin-peroxidase complex (1:400, Amersham). Peroxidase activity was detected with $\mathrm{DAB} / \mathrm{H}_{2} \mathrm{O}_{2}$.

In situ hybridization. Adult mice were fixed by perfusion with $4 \%$ paraformaldehyde, post-fixed for $30 \mathrm{~min}$, and sectioned at $200 \mu \mathrm{m}$ on a vibrating slicer. Sections were treated with X-gal for $6 \mathrm{hr}$, rinsed in PBT, and dehydrated in graded methanol/PBT series. Rehydrated sections were treated for the revelation of GAD 67 transcripts using digoxigeninUTP (Boehringer Mannheim, Mannheim, Germany)-labeled probes. The rat GAD 67 no. 14 subclone (Erlander et al., 1991) was linearized with SalI and transcribed using the Riboprobe Gemini System II kit (Promega, Madison, WI) and T3 RNA polymerase. In situ hybridization was performed as described for whole-mount preparations (Wilkinson, 1992) except that the sections were stored overnight at $-20^{\circ} \mathrm{C}$ after prehybridization. The next day, the sections were heated at $70^{\circ} \mathrm{C}$. After a change in the prehybridization buffer, the probe was added at a concentration of $10-20 \mu \mathrm{g} / \mathrm{ml}$, and the sections were hybridized at $70^{\circ} \mathrm{C}$ overnight in a water bath. An anti-digoxigenin alkaline phosphatasecoupled antibody (Boehringer Mannheim) was used diluted 1:2000; alkaline phosphatase activity was revealed using nitro blue tetrazolium/5bromo-4-chloro-3-indoyl phosphate as substrate.

Organotypic cultures. All products were purchased from Life Technologies, unless specified otherwise. Embryos were recovered from euthanized pregnant females, and their brains were dissected out and collected individually in PBSG. The H2-Z1 transgenic embryos were identified as follows. In E13.5 and older embryos, the telencephalon and pontine region were separated, and the pontine fragments were tested for $\beta$-galactosidase activity using a rapid fluorescence detection test as described previously (Cohen-Tannoudji et al., 1994). Embryos from E10.5 to E12.5 H-2Z1 litters were used for transplantation without previous transgene detection. Two parietal and two occipital grafts were dissected from each embryo and transplanted in homotopic or heterotopic locations in E13.5-E15.5 whole cortical explants. The donor embryo was a posteriori identified as being transgenic provided that a single transplant expressed $\beta$-galactosidase; if not, the whole series was discarded. In this case all the transplants originating from this embryo were scored. In the case of E12.5-dissociated grafts, transgenic embryos were identified using PCR amplification of the lacZ sequence in yolk sac fragments using the following primers: $5^{\prime}$-gtc gtt tta caa cgt cgt gac t; $3^{\prime}$-gat ggg cgc atc gta acc gtg c.

PCR cycles were $95^{\circ} \mathrm{C}, 8^{\prime}$ followed by 25 cycles of $95^{\circ} \mathrm{C}, 1^{\prime}$ and $55^{\circ} \mathrm{C}, 2^{\prime}$. DNA amplification yielded a $270 \mathrm{bp}$ lacZ fragment, and the whole procedure lasted $<2.5 \mathrm{hr}$.

Meningeal tissue was removed manually from telencephalic vesicles older than E13.5. At earlier stages, the dissected brains were first incubated $30 \mathrm{~min}$ on ice in an enzymatic solution containing $0.125 \%$ trypsin, $0.15 \%$ pancreatin, and $0.01 \%$ versene in saline. Washing and subsequent dissections were performed in L-15 medium supplemented with 5\% heat-inactivated horse serum. Presumptive hippocampus, cingular cortex, septum, and ganglionic eminences were removed from "whole cortex" explants. The olfactory bulb was left for anteroposterior orientation.

Whole cortical explants were laid ventricular side down on a $0.4 \mu \mathrm{m}$ Biopore membrane (Millipore, Bedford, MA) floating in a $35 \mathrm{~mm}$ Petri dish and cultured at $37^{\circ} \mathrm{C}$ in a humidified atmosphere containing $5 \%$ $\mathrm{CO}_{2}$. Explants were floated on $1 \mathrm{ml}$ of the following culture medium: 1:1 DMEM/F12 with $2 \mathrm{mM}$ L-glutamine, $33 \mathrm{~mm}$ D-glucose, $3 \mathrm{~mm}$ sodium bicarbonate, $10 \mathrm{~mm}$ HEPES, pH 7.4, buffer $50 \mathrm{IU}-50 \mu \mathrm{g} / \mathrm{ml}$ of penicillin-streptomycin supplemented with heat-inactivated serum (fetal calf serum, 10\%, Biological Industries; horse serum, 5\%, Life Technologies). After $24 \mathrm{hr}$ in vitro the antibiotic concentration was lowered to $5 \mathrm{IU}-5$ $\mu \mathrm{g} / \mathrm{ml}$. Medium was changed every $2 \mathrm{~d}$ until the transgenic cortex reached the equivalent of P5-P7. In preliminary experiments, $400-\mu \mathrm{m}$-thick coronal slices were obtained from embryonic brains embedded in 3\% agar in PBS using a vibrating slicer and processed as above.

Explants still attached on the membranes were fixed by immersion in the same way as embryos; they were detached from the membranes before further processing. The telencephalic vesicles where processed for the detection of $\beta$-galactosidase as described above. Explants were postfixed in $4 \%$ paraformaldehyde and stored at $4{ }^{\circ} \mathrm{C}$ in a $1: 1$ mixture of $4 \%$ paraformaldehyde and glycerol.

Grafting. Grafts were dissected out with a scalpel blade and implanted into host telencephalic vesicles using a glass pipette. Reaggregates were obtained from pooled transgenic E12.5-E14.5 parietal cortices by trituration in PBSG with a polished Pasteur pipette, followed by several centrifugation rounds at $800 \mathrm{rpm}$. They were processed as solid explants.

\section{RESULTS}

\section{Expression of the $\mathrm{H}-2 \mathrm{Z} 1$ transgene}

In $\mathrm{H}-2 \mathrm{Z} 1$ mice the lacZ transgene is expressed in the parietal cortex beginning from postnatal day 2. H-2Z1 expression is first restricted to two convergent rows of cells located in the primary and secondary somatosensory cortex, respectively (CohenTannoudji et al., 1994; Gitton et al., 1999). The blue domain 
enlarges progressively until delineating exactly the somatosensory cortex; maximum expression is observed during the second postnatal week. The characteristic modular pattern of the mouse somatosensory cortex is directly detectable on X-gal-stained brains at $\sim$ P6 (Fig. 1 $A, B$ ). Transgene expression is restricted to layer IV neurons of the somatosensory cortex (Fig. 1C) and to a scattered population of deep layers cells that are more numerous in a restricted area of the occipital cortex. This nonsomatosensory layer IV expression was minimal in the crosses used in the present and previous studies, but it increased markedly in other genetic backgrounds (our unpublished observation).

In a previous transplantation study, we found that cells were already committed to express H-2Z1 at E13.5 (Cohen-Tannoudji et al., 1994). The aim of the present study was first to better characterize the H-2Z1-expressing cells. We wondered in particular whether $\mathrm{H}-2 \mathrm{Z} 1$ was expressed in a cell type that could participate in the maintenance or transmission of regional information or alternatively could modulate cortical function in a somatosensory-specific way. Second, a sharp delimitation of $\mathrm{H}-2 \mathrm{Z} 1$ expression was observed in some grafts in previous transplantation experiments. This could result from the displacement of the blue cells under the influence of local cues present in the host cortex. Alternatively, the somatosensory primordium could be strictly delimited with minimal tangential movements. In the present study, we examined the regionalization of transgene expression in the complete absence of thalamic or subcortical cues. Finally, previous heterochronic transplantations have shown that fragments of E13.5 H-2Z1 cortex maintain their presumptive expression of the transgene when grafted heterotopically in a newborn host cortex. To determine whether somatosensory identity was plastic under the influence of signals present at earlier stages, E11.5-E13.5 transgenic cortex was apposed to ectopic embryonic telencephalic tissues as putative sources of regionalizing signals, and $\mathrm{H}-2 \mathrm{Z} 1$ expression was tested at later stages.

\section{Characterization of $\mathrm{H}-2 \mathrm{Z1}$-expressing cells in layer IV of the somatosensory cortex}

DiI crystals placed in several cortical regions after X-gal revelation did not label H-2Z1-positive cells, indicating that the blue cell processes were confined to the vicinity of layer IV. Thus $\mathrm{H}-2 \mathrm{Z} 1$ could be expressed in a subset of layer IV astrocytes or in interneurons. The H-2Z1-positive cells in layer IV did not express high levels of $\beta$-galactosidase. In particular, because their cell bodies were not filled by the reaction product, no cue about their shapes could be obtained by X-gal staining. With the hope that it could outline the H-2Z1-positive cells and provide indications about their size, shape, and distribution, we used a diffusible substrate of $\beta$-galactosidase. FDG is a nonfluorescent molecule that is cleaved by $\beta$-galactosidase, leading to the liberation of fluorescein. Under hypotonic conditions, incubation of unfixed tissues with FDG results in a transient accumulation of fluorescein into $\beta$-galactosidase-expressing cells before it diff uses in the tissue. Sections obtained from a P14 transgenic brain using a vibrating slicer were placed on a slide in a drop of FDG and observed immediately. In the parietal cortex, a row of fluorescent cell bodies was clustered in a layer identified as layer IV on the basis of its barrel organization (Fig. 1D). Some intensely fluorescent cells were observed in deeper layers. The H-2Z1 fluorescent cell bodies in layer IV had an apparent diameter of 15-25 $\mu \mathrm{m}$ and appeared polyhedral with a main apical dendrite (Fig. $1 E$ ). Several processes extended from the cell body. Individual fluorescent axons were observed transiently but were rapidly undetectable because of the background fluorescence that filled the whole barrel. Because FDG seemed to label axons more readily than dendrites, we reexamined the localization of the X-gal precipitate at high magnification in vibratome sections of fixed tissue. In neurons expressing the $\mathrm{H}-2 \mathrm{Z} 1$ transgene, the blue stain was localized to thin puncta that accumulated in a few cytoplasmic locations (Fig. $1 F$, arrowhead) that were visible as spots at low magnification and probably represent Golgi complexes. Thin blue rods were also observed in the vicinity of the X-gal-positive cells. They sometimes accumulated around unlabeled neurons or on small vessels (Fig. 1G, arrowheads), suggesting that X-galcontaining vesicles were also present in some axons.

$\mathrm{H}-2 \mathrm{Z} 1$ was not expressed in all layer IV neurons. Possible colocalization of $\beta$-galactosidase with some cell type-specific markers was examined. The blue cells did not contain GFAP (data not shown), an astrocyte marker, confirming their neuronal nature. A higher density of GAD 67-expressing neurons was observed at the limit between layers IV and V in the somatosensory cortex, raising the possibility that $\mathrm{H}-2 \mathrm{Z} 1$ could mark a subpopulation of GABAergic interneurons. X-gal-reacted sections of adult mouse cortex were treated by nonradioactive in situ hybridization for the detection of GAD 67 transcripts. The GAD 67- and H-2Z1-expressing populations were completely distinct (Fig. $1 H$ ). In addition, there was no overlap between the populations of $\beta$-galactosidase-expressing cells and the neuronal populations immunoreactive for the calcium-binding proteins calretinin (Fig. 1I) and parvalbumin (Fig. 1J), which are mostly composed of GABAergic interneurons. Some $\beta$-galactosidaseexpressing cells were immunoreactive for calbindin (Fig. $1 K$ ). These observations indicate that $\mathrm{H}-2 \mathrm{Z1}$ is expressed in nonGABAergic modified pyramidal cells.

\section{In vitro development of $\mathbf{H}-2 \mathrm{Z} 1$ expression}

In preliminary experiments, $400-\mu \mathrm{m}$-thick E15.5 transverse cortical slices were cultured on floating Biopore membranes for $10 \mathrm{~d}$ (equivalent to $\mathrm{P} 7$ in vivo). The tangential dimension of the $\mathrm{H}-2 \mathrm{Z} 1$ expression domain was similar to that observed in vivo (Fig. $2 B, C$, between arrowheads). In contrast, the spreading of the slices on the membrane resulted in an uncontrolled sliding of the somatosensory area in the radial dimension. This was partially prevented by maintaining the agarose embedding used for vibratome sectioning around the slices (Fig. $2 C$ ). However, in this condition, the growth of the explants was constrained in a direction perpendicular to the membrane, resulting in poor survival. Therefore, to maintain the topography in cortical explants, whole cortical explants were dissected from telencephalic vesicles and cultured ventricular side down (Fig. $2 A$ ). In most cases, blue-yellowish macrophages were scarcely distributed in the explants and were easily distinguished from the blue $\mathrm{H}-2 \mathrm{Z} 1$ layer IV neurons. However, the macrophages accumulated on degenerating explants. In addition, as mentioned above, a few deep-layer H-2Z1-expressing cells were observed outside the somatosensory area. For these reasons, explants containing only scattered blue cells were always considered negative for area-specific transgene expression.

After $12 \mathrm{~d}$ in vitro, E13.5 telencephalic vesicle explants developed a regionalized expression of the transgene (Fig. 2D). In addition, the laminar restriction of $\beta$-galactosidase expression was preserved (Fig. 2E). In some cases, the deep layers of the explant appeared to degenerate. The survival and growth of younger explants was poorer; nevertheless a clear regionalized expression of the transgene was also observed at E12.5 (data not shown). Because the long-term survival of explants younger than E13.5 

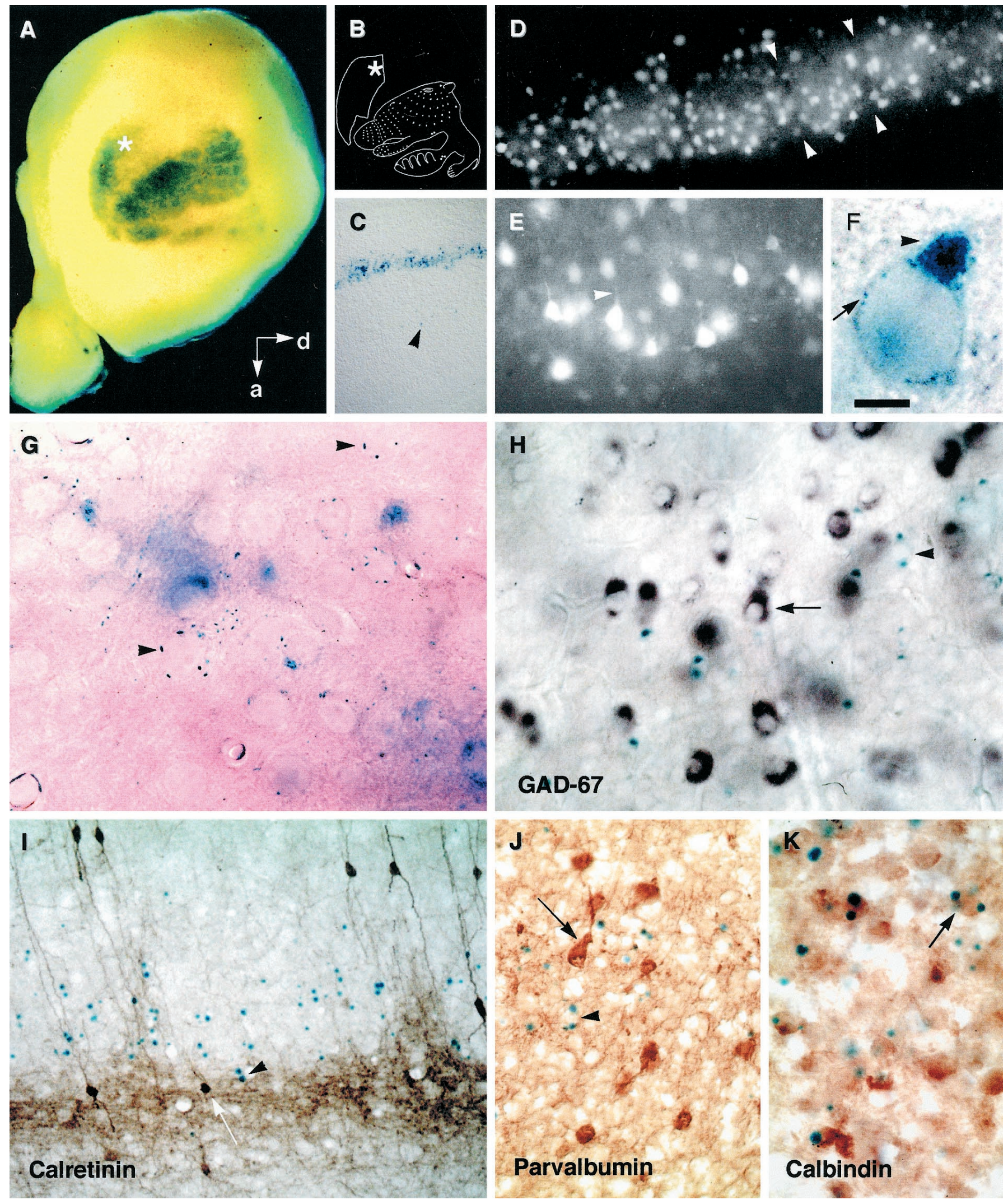

Figure 1. Characterization of the cells that express the $\mathrm{H}-2 \mathrm{Z} 1$ transgene in the cerebral cortex: $A-G, \beta$-galactosidase activity is visualized as a blue (A, $C, F-K$ ) or a fluorescence (white in $D, E$ ) reaction product. $A$, Whole-mount staining of the right telencephalic hemisphere of a P8 $\mathrm{H}-2 \mathrm{Z} 1 \mathrm{mouse}$ oriented to provide an upright position to the somatotopic body representation disclosed by transgene expression, which is schematized in $B$ [modified from Dawson and Killakey (1987)]. The in situ orientation is given by the arrows. $d$, Dorsal; $a$, anterior. The asterisks mark additional staining, probably located in the secondary somatosensory area. $C$, Sagittal section of a P8 brain illustrating the layer-specific expression of the H-2Z1 transgene; the arrowhead marks a deep neuron that expresses $\beta$-galactosidase. D, E, The diffusible substrate FDG fills the cell bodies (Figure legend continues) 


\section{A}

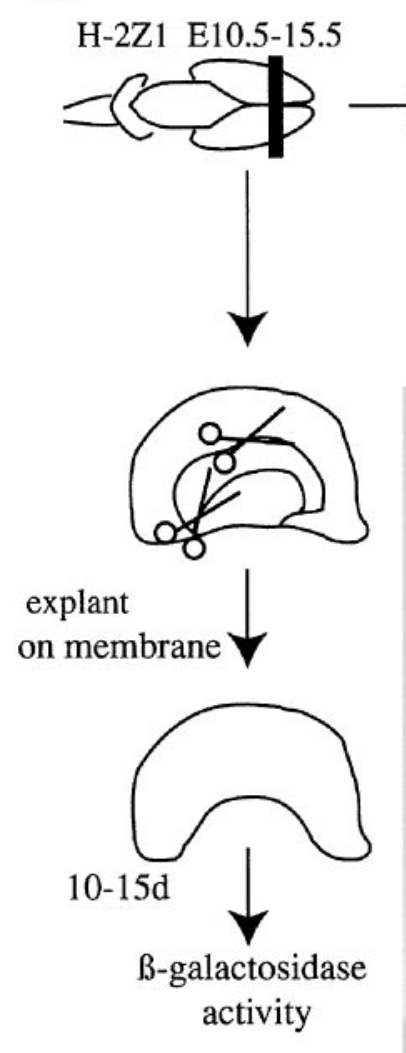

B

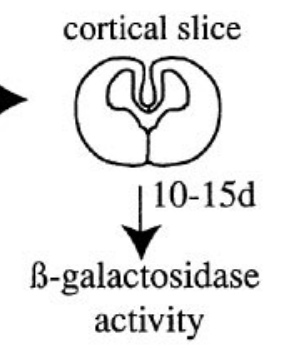

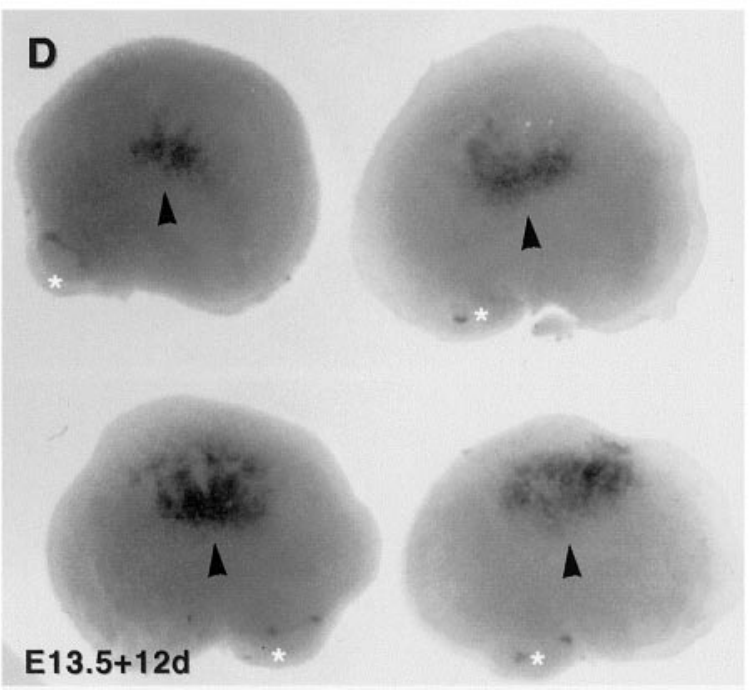
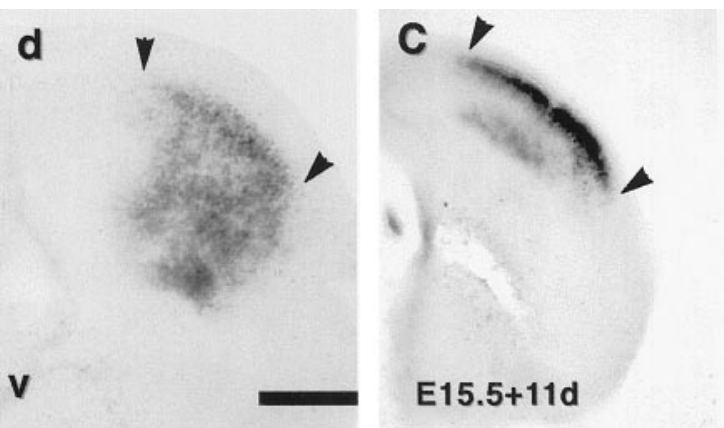

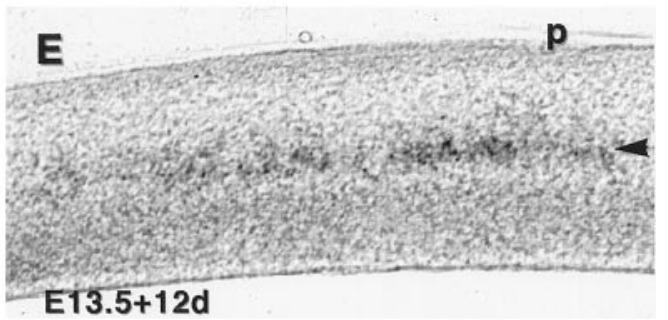

$E 13.5+12 d$
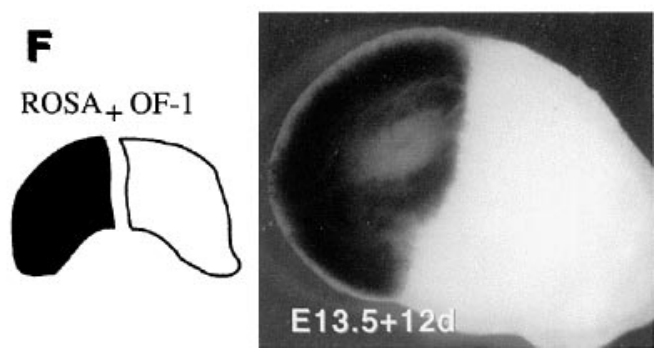

Figure 2. Development of H-2Z1 expression in vitro visualized by the blue detection of $\beta$-galactosidase activity. $A$, Slices and whole cortical explant dissections are schematized on the left of the corresponding figures. The left column illustrates the dissection of a left telencephalic vesicle. Both the hippocampus and ganglionic eminence are removed from whole cortical explants. $B, C$, Vibratome slices $(400 \mu \mathrm{m}$ thick) of E15.5 H-2Z1 cortex cultivated for $11 \mathrm{~d}$. The agarose embedding was removed in $B$ but left in place in $C$. The flattening of the slices on the Biopore membrane substrate results in the radial spreading of the $\mathrm{H}-2 \mathrm{Z} 1$ neurons during culture time. The mediolateral extent of the expression domain (between arrowheads) is not markedly modified. $d$, Dorsal; $v$, ventral. $D, E$, Regionalized expression of the $\mathrm{H}-2 \mathrm{Z} 1$ transgene (arrowheads) developed after $12 \mathrm{~d}$ in vitro in E13.5 whole cortical explants. E, Transverse vibratome section through one of the explants showing the laminar organization of transgene-expressing cells (arrowhead). Tangential cell mixing is minimal in whole cortical explants. $p$, Parietal. $F$, Half cortical explants taken from E13.5 rosa-26 (which express ubiquitously lacZ) and OF-1 wild-type mice were juxtaposed. Cell mixing between the two genotypes is minimal. Scale bar (shown in $B$ ): $B, 400 \mu \mathrm{m} ; C, 250 \mu \mathrm{m} ; D$, $1.2 \mathrm{~mm} ; E, 200 \mu \mathrm{m} ; F, 1 \mathrm{~mm}$.

was suboptimal, in subsequent transplantation experiments the host cortex was dissected from E13.5-E15.5 nontransgenic embryos (see below).

The restricted pattern of H-2Z1 expression in E12.5-E13.5 cortical explants indicated that the presumptive somatosensory area is well delimited and that the presence of thalamic axons is not required to gather or prevent the dispersion of the blue somatosensory neurons. However, whether any tangential dispersion did occur in our culture conditions was unknown. To examine this point, we confronted two E13.5 telencephalic vesicle halves, one of which (either the anterior or the posterior half) was dissected from rosa-26 mice, which contain an ubiquitously expressed lacZ reporter gene. The explants were then maintained for $12 \mathrm{~d}$ in vitro. Cell mixing was minimal in these explants (Fig.
$2 F)$, although some cell mixing did sometimes occur on the ventricular side. These observations indicate that in the absence of local perturbation, tangential migrations are not extensive in whole cortical explants.

\section{Isochronic transplantations of E13.5 H-2Z1 cortex}

Fragments of E13.5 H-2Z1 occipital or parietal cortex were grafted into whole flat-mounted cortical primordia dissected from nontransgenic hosts at a similar stage (E13.5-E15.5) (Fig. 3A). The parietal and occipital grafts were inserted into the occipital (Fig. 3B) or parietal (Fig. 3C) regions, respectively, of the host cortex. In the latter case the ungrafted parietal region of the donor cortex was cultured in parallel as a positive control of transgene expression and to check whether the parietal domain

of H-2Z1-positive cells; the arrowheads delineate a single barrel in $D$ and labeled neurites in $E . F, G, \beta$-galactosidase activity is localized to small vesicles in the cell body (arrow in $F$ ) that accumulate in one to three locations in the cytoplasm (arrowhead in $F$ ) and seem to mark some axons (arrowheads in $G) . H-J$, Transverse sections through the somatosensory area of young adult mice treated by double-labeling for the detection of H-2Z1 expression (in blue, arrowheads in $H-K$ ) and GAD 67 ( purple, arrow in $H$ ), calretinin (brown, arrow in $I$ ), parvalbumin (brown, arrow in $J$ ), or calbindin (brown, arrow in $K$ ). H-2Z1 was never colocalized with GAD 67, calretinin, or parvalbumin. In contrast, some H-2Z1-positive cells coexpressed calbindin. Scale bar (shown in F): $A, 400 \mu \mathrm{m} ; C, 1 \mathrm{~mm} ; D, 100 \mu \mathrm{m} ; E, H, 35 \mu \mathrm{m} ; G, K, 20 \mu \mathrm{m} ; I, J, 50 \mu \mathrm{m}$. 

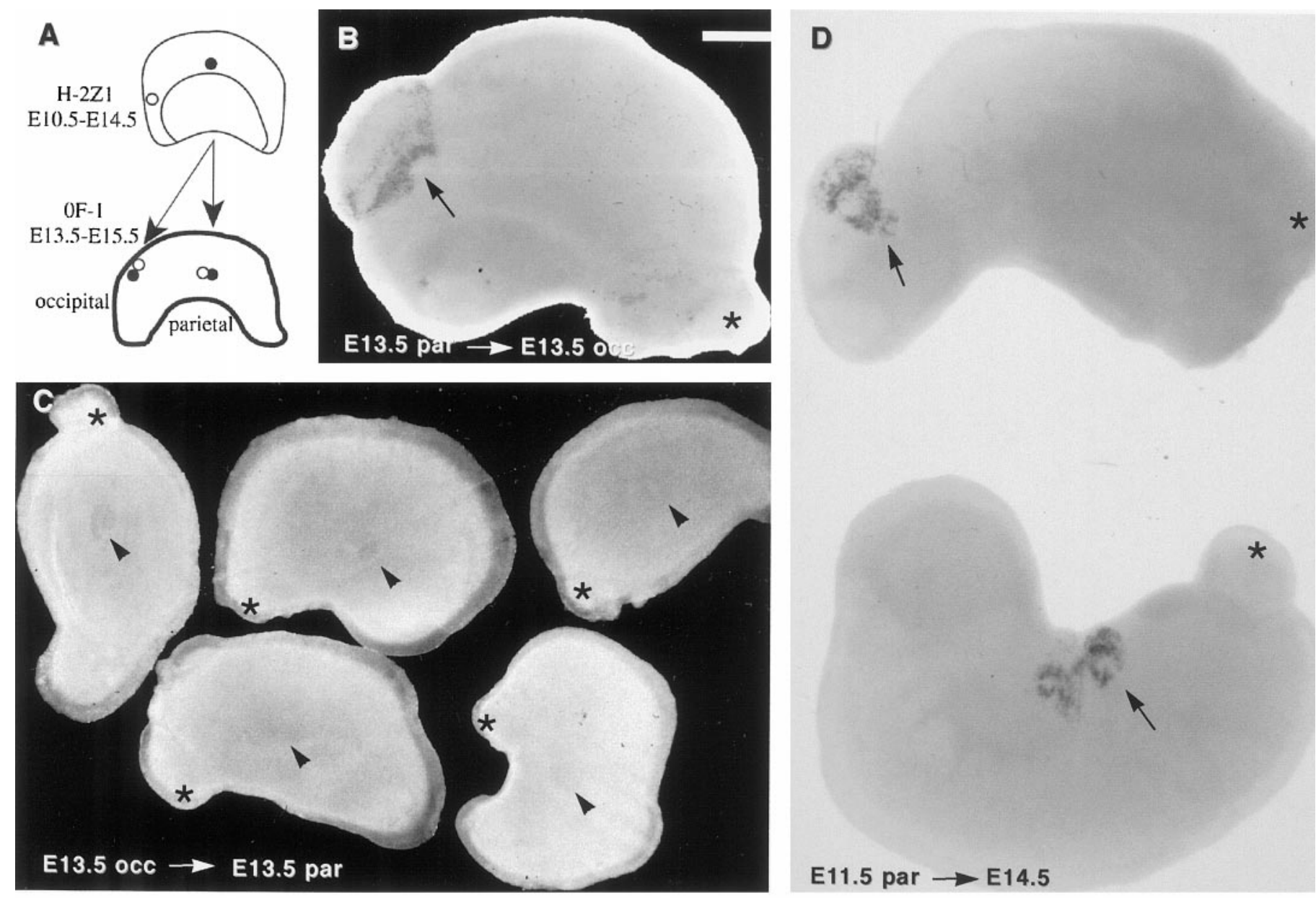

$\mathrm{E} 11.5 \mathrm{par} \rightarrow \mathrm{E} 14.5$
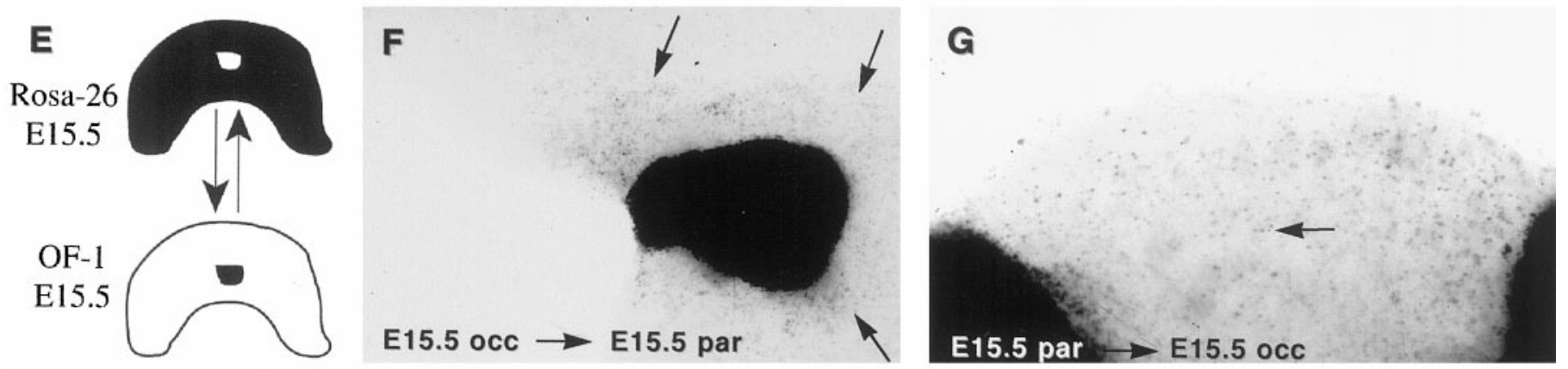

Figure 3. H-2Z1 expression develops in grafts transplanted heterotopically into an embryonic cortex. $A$, Schematic representation of the grafting procedure. Parietal (solid circle) or occipital (empty circle) grafts are transplanted in the occipital or parietal regions, respectively, of whole cortical explants. $B, C$, Heterotopic and isochronic transplantation of parietal (arrow in $B$ ) or occipital (arrowhead in $C$ ) E13.5 $\mathrm{H}-2 \mathrm{Z} 1$ grafts in nontransgenic whole cortical explants. $\beta$-galactosidase is expressed in parietal grafts developing in either location, whereas occipital grafts remain unstained. $D$, E11.5 H-2Z1 parietal cortex grafts transplanted into the occipital (top explant, arrow) or parietal (bottom explant, arrow) region of E14.5 nontransgenic whole cortical explants develop a robust expression of $\beta$-galactosidase. The asterisks in $B-D$ label the olfactory bulb. $E-G$, In contrast to what occurs when the explants receive a sharp cut, the exchange of grafts between rosa-26 and OF-1 E15.5 embryos results in widespread cell mixing (arrows in $F$, $G$ ) between graft and host. Scale bar (shown in $B$ ): $B, D, 500 \mu \mathrm{m} ; C, 250 \mu \mathrm{m} ; F, G, 400 \mu \mathrm{m}$.

was left intact. In 21 of 24 cases $(87 \%)$ (Table 1), the grafts, cultivated for 11-13 d in vitro, maintained their presumptive expression of the transgene. Because of its proximity, the lateral ganglionic eminence could provide positional cues important for parietal cortex individualization. To test for the presence of such signals at E13.5, fragments of nontransgenic lateral ganglionic eminence were grafted into the occipital region of E13.5 H-2Z1 whole cortical explants. No induction was observed around gan- glionic eminence grafts in transplants examined $12 \mathrm{~d}$ later (data not shown).

As a visual test of host-graft communication, fragments of rosa-26 embryonic cortex were transplanted homotopically or ectopically into wild-type cortical explants. The reciprocal grafts were also performed (Fig. $3 E$ ). In 7 of 7 cases, the rosa-26 transplants were surrounded by a halo of blue cells with no preferential direction for migration (Fig. $3 F$ ). Reciprocally, non- 


\begin{tabular}{|c|c|c|c|c|}
\hline Donor grafts & $\begin{array}{l}\text { Host telencephalic } \\
\text { vesicles }\end{array}$ & $\begin{array}{l}\beta \text {-gal- } \\
\text { positive } \\
\text { grafts }\end{array}$ & $\begin{array}{l}\beta \text {-gal- } \\
\text { negative } \\
\text { grafts }\end{array}$ & $\begin{array}{l}\% \text { of grafts } \\
\text { maintaining } \\
\text { presump- } \\
\text { tive expres- } \\
\text { sion }\end{array}$ \\
\hline \multirow[t]{3}{*}{ E13.5 parietal } & Parietal E15.5 & 2 & 0 & 100 \\
\hline & Occipital E15.5 & 5 & 1 & 83 \\
\hline & Occipital E13.5 & 7 & 1 & 88 \\
\hline E13.5 occipital & Parietal E13.5 & 1 & 7 & 88 \\
\hline E12.5 parietal & Occipital E16.5 & 7 & 2 & 78 \\
\hline E12.5 occipital & Parietal E13.5 & 0 & 9 & 100 \\
\hline \multirow[t]{2}{*}{ E11.5 parietal } & Parietal E14.5 & 14 & 1 & 93 \\
\hline & Occipital E14.5 & 10 & 6 & 63 \\
\hline \multirow[t]{2}{*}{ E11.5 occipital } & Parietal E14.5 & 1 & 8 & 89 \\
\hline & Occipital E14.5 & 1 & 9 & 90 \\
\hline
\end{tabular}

transgenic transplants were invaded by blue cells from the transgenic host (Fig. 3G). This indicates that cell mixing is promoted by the manipulation of graft and host tissue needed by the transplantation procedure and suggests that reciprocal signaling between graft and host can take place in this in vitro paradigm.

\section{Early specification of $\mathrm{H}-2 \mathrm{Z} 1$ expression}

Fragments of $\mathrm{H}-2 \mathrm{Z} 1$ transgenic parietal cortex were dissected from younger embryos (E10.5-E13.5) and grafted into the parietal or occipital regions of E13.5-E16.5 whole cortical explants. E11.5-13.5 explants maintained their presumptive expression of the transgene (Table 1). However, a smaller proportion of E11.5 parietal H-2Z1 grafts expressed $\beta$-galactosidase when transplanted into the occipital than when transplanted into the parietal region of a host cortex $(63 \%, n=16$ vs 93\%, $n=15)$. Well integrated E11.5-E13.5 transplants organized in layered rosette structures (Fig. 3D), as observed previously in some E13.5 explants grafted in vivo (Cohen-Tannoudji et al., 1994). Some transgenic parietal fragments did not integrate well into the host whole cortical explant and formed an isolated protrusion on the Biopore membrane. The number of transgene-expressing cells was much reduced in these transplants when compared with other grafts in the same experiment. This observation was interpreted as confirming that transplants younger than E13.5 require a trophic support from the host for survival.

There was a marked difference in the case of E10.5 transplants: even large transplants never developed $\beta$-galactosidase expression $(n=39)$. Rosa-26 E10.5 transplants maintained in the same culture conditions did not grow. To obtain a better survival, H-2Z1 E10.5 explants were cultured with attached meninges or without meninges but after a 1 hr treatment with basic FGF (0.1 $\mu \mathrm{g} / \mathrm{ml})$. The presence of meninges permitted the differentiation of a few H-2Z1-expressing cells in 1 of 8 cases. Small but detectable rosa-26 transplants were recovered from E10.5 grafts that kept their meninges after transplantation in E14.5 OF-1 hosts (4 of 5). A short treatment with basic FGF had no detectable effect on E10.5 explant growth or survival.

To determine whether the absence of a particular type of pioneer neurons could explain the lack of in vitro differentiation of E10.5 explants, we compared the early neuronal populations immunoreactive for $\mathrm{TuJ}-1$, calbindin, and calretinin in the E10.5 and E11.5 parietal cortex. At E10.5, the TuJ-1immunoreactive neurons were scattered over the cortical sur- face, whereas the calbindin-immunoreactive neurons were restricted to a crescent located beneath the edge of the olfactory placode and to a band in the preoptic region (data not shown). No calretinin-immunoreactive neurons were observed. At E11.5, there was a large increase in the density of TuJ-1immunoreactive cells. The calbindin-positive neurons now overlaid the striatal region and the dorsalmost (presumptive hippocampus and/or cingular cortex) and caudalmost (presumptive occipital cortex) parts of the cortex. Calretinin-positive neurons were located at this stage over the striatum and parietal cortex. Thus, a population of calretinin-positive neurons differentiates in the parietal cortex between E10.5 and E11.5. To test whether this first step could proceed in vitro, whole telencephalic vesicles of E10.5 embryos were cultured for $24 \mathrm{hr}$ on Biopore membranes. Some littermates were fixed immediately as controls and processed in parallel with the explants for calretinin immunoreactivity. The differentiation of calretinin neurons proceeded normally in vitro (Fig. 4, compare $A, B$ ). Thus, the early population of calretinin neurons is probably not responsible for the difference observed between E10.5 and E11.5 transplants in their proliferative capacity in vitro.

\section{Dissociation of somatosensory cortex neurons}

The experiments described above indicated that "somatosensory identity" is a robust property of parietal transplants that is established at the time when the first postmitotic cortical neurons are generated and may still be partially plastic by E11.5. This suggested that persistent cell-cell contacts could maintain areal identity in cortical fragments. We therefore examined whether dissociation of cells before grafting would increase their susceptibility to extrinsic influences. The effect of dissociation on H-2Z1 expression was tested at E12.5, E13.5, or E14.5. Fragments of parietal H-2Z1 cortex of a given age were dissected, pooled, and dissociated into single cells (Fig. 4C). The dissociated cells were pelleted by centrifugation. Small reaggregates cut from the pellet were transplanted into $2 \mathrm{~d}$, older whole cortical explants in the same way as cortical fragments. The reaggregates contained some isolated blue cells. The difference between the reaggregates and the solid explants was that the X-gal-containing cells did not form a layer but remained scattered throughout the graft (Fig. 4D). The aspect of the reaggregates was not modified with the donor age or the site of transplantation.

\section{DISCUSSION}

We show here that the $\mathrm{H}-2 \mathrm{Z} 1$ transgene is expressed in nonGABAergic interneurons of layer IV. In this and previous studies we have used expression of the $\mathrm{H}-2 \mathrm{Z} 1$ transgene as a marker of somatosensory area in the mouse cerebral cortex. In an earlier study (Cohen-Tannoudji et al., 1994), we found that fragments of E13.5 H-2Z1 cortex maintain their regional identity when grafted heterotopically in nontransgenic newborn hosts. These observations indicated that if signals able to modify the somatosensory fate of E13.5 explants existed, they were no longer present in the postnatal host.

To study the development of area-specific properties, we developed an in vitro explant system. We found that whole cortex explants maintain their regionalization and develop a layerspecific expression of the transgene during the extended culture period necessary to obtain H-2Z1 expression. From E12.5 on, in the absence of noncortical cues (except for the olfactory bulb), $\mathrm{H}-2 \mathrm{Z} 1$ expression was restricted to the parietal region of explants. The result of explantation and transplantation studies indicated 


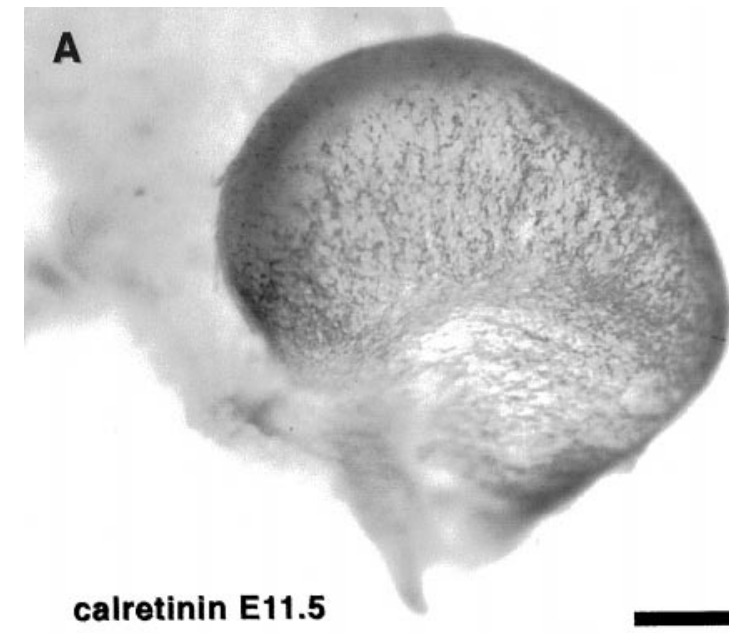

calretinin E11.5

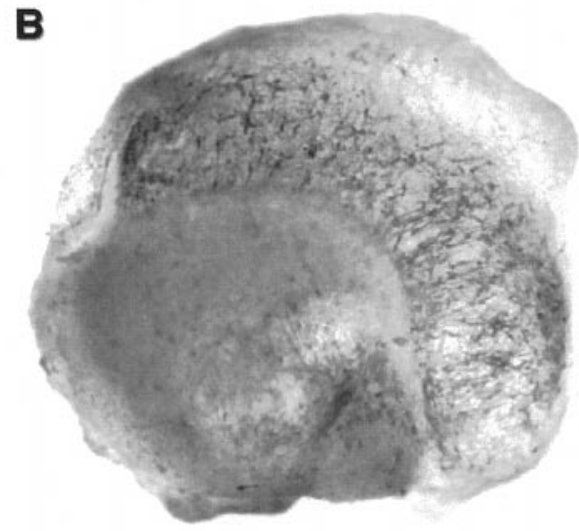

calretinin E10.5+1d

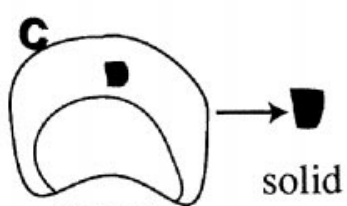

$\mathrm{H}-2 \mathrm{Z} 1$

E12.5-E14.5

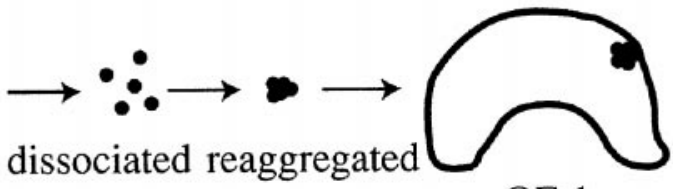

OF-1

E13.5-E15.5

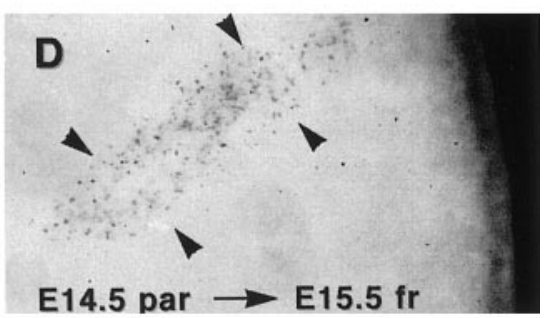

Figure 4. Pioneer neurons develop between E10.5 and E11.5 in vitro. A, Calretinin-positive neurons appear in the parietal cortex at E11.5. B, Calretinin neurons develop similarly in E10.5 telencephalic explants maintained in culture for $1 \mathrm{~d}$. $C$, Schematic representation of the dissection, dissociation, and reimplantation of aggregates. $D$, E14.5 parietal H-2Z1 reaggregate reimplanted in the anterior cortex of a E15.5 whole cortical explant, cultivated for $11 \mathrm{~d}$, and treated with X-gal. Dissociation of parietal grafts results in a sharp decrease in the number of cells and the level of $\beta$-galactosidase expression, which is somewhat over-revealed in this picture. Scale bar (shown in $A$ ): $A, B, 550 \mu \mathrm{m} ; D, 200 \mu \mathrm{m}$.

that, beginning from E13.5, embryonic explants were regionalized and can be used as a source of ectopic signals for small cortical grafts. We tested E13.5 ganglionic eminence and E13.5-E15.5 parietal cortex as possible sources of parietal signals and found that they could not induce $\beta$-galactosidase expression in E11.5E13.5 occipital transgenic cortex. Thus occipital cortex cannot be induced to express $\mathrm{H}-2 \mathrm{Z} 1$ under the influence of putative "parietal" signals. In contrast, the parietal cortex phenotype was partially plastic at E11.5: the proportion of grafts expressing $\mathrm{H}-2 \mathrm{Z} 1$ in the occipital regions of whole cortical explant hosts $(63 \%)$ was lower compared with the parietal region (93\%). Finally, to increase the access of putative modifying signals to the embryonic transgenic cortex and to test the role of cell-cell communication within the explants, we used dissociated and reaggregated explants. Dissociation and reaggregation decreases the number of $\mathrm{X}$-gal-containing cells. In addition, the pattern of $\beta$-galactosidase expression in reaggregates is not modified by the age of donor or host and the site of transplantation. These observations were interpreted as showing that the commitment to a somatosensory identity takes place within the parietal neuroepithelium at the onset of neuronal production.

\section{Characterization of the $\mathrm{H}-2 \mathrm{Z1}$-positive neurons in the somatosensory cortex}

Astrocytes deriving from radial glia could inherit and transmit an early regional identity (Bittman et al., 1997; Owens and Kriegstein, 1998). In addition, they are among the cell types that display area-specific properties. In particular, a somatosensory cortex-specific regulation of the deposition by astrocytes of extracellular matrix proteins has been described (Steindler et al.,
1989). Locally produced GABAergic interneurons are also good candidates for an area-specific cell population because of their diversity. They could modulate cortical function in an areaspecific way. It is unlikely, however, in view of the observed characteristics of the H-2Z1-positive cells, that they represent a somatosensory cortex-specific subset of astrocytes or GABAergic interneurons. Their shape, birthdate [approximately E14.5 (Cohen-Tannoudji et al., 1994; Y. Gitton, unpublished observation)], lack of GFAP expression, and absence of migration in explants argue in favor of their neuronal identity. We found no colocalization of $\beta$-galactosidase activity with GAD 67 transcripts. Because optimal conditions for the detection of $\beta$-galactosidase activity were at first not compatible with a sensitive detection of GAD 67 transcripts, we also compared the distribution of the H-2Z1-positive neurons with that of neurons expressing different calcium-binding proteins, the majority of which are GABAergic (for review, see DeFelipe, 1993). The H-2Z1-positive neurons expressed neither calretinin nor parvalbumin but sometimes coexpressed calbindin, a less specific marker in the rat (DeFelipe, 1993). Our observations indicate that the blue cells are non-GABAergic interneurons. However, we could not relate more precisely the $\mathrm{H}-2 \mathrm{Z} 1$ cells to the morphological cell subtypes that have been described in layer IV of the mouse somatosensory cortex.

\section{The somatosensory primordium is restricted}

In our previous transplantation experiments, parietal and occipital transplants clearly differed in their capacity to express $\beta$-galactosidase, but the density of blue cells varied between parietal grafts and was not always uniform in a single transplant. 
How precisely the prospective somatosensory area was delimited in embryos remained unclear. In particular we wondered whether the blue cells were first produced over a large fuzzy area and later gathered around thalamic axon bundles allowing the endogenous "somatosensory identity" of the cortex to coincide with the thalamic one. If this were indeed the case, we expected the blue cells to be more scattered in the absence of thalamic afferents. We observed a restricted area labeled by X-gal in whole cortical explants and slices, indicating that the somatosensory anlage is not diffuse but well delimited. Tangential dispersion was not important in these explants, as indicated by the modest cell mixing observed at the interface between rosa 26 and OF-1 cortices, which are left relatively undisturbed by the cut in contrast to what occurs during the transplantation procedure. The possibility that the immature precursors of $\mathrm{H}$-2Z1-positive cells become motile under the influence of thalamic axons cannot be ruled out.

\section{The parietal cortex acquires a "somatosensory identity" by the time the first postmitotic neurons are produced}

At E11.5, parietal and occipital transplants differed in their capacity to express the $\mathrm{H}-2 \mathrm{Z} 1$ transgene, indicating that somatosensory identity is acquired at or before this developmental stage. The difference in the proportion of E11.5 parietal transplants that express $\beta$-galactosidase when grafted in parietal or occipital regions of whole cortical explants (63 vs 93\%; $p<0.05$ ) suggests that the development of somatosensory identity is still plastic in E11.5 explants and can be modified under the influence of environmental cues; however, this observation must be considered cautiously. The difference in maturation between the occipital and parietal domains of the host cortical explant could result in nonspecific variations in trophic support to the graft.

The observation that early regional identity in the cerebral cortex becomes determined around the time of first neuronal production is consistent with the result of transplantation experiments involving the rat cerebral cortex (E12) (Barbe and Levitt, 1991) or chick optic tectum (E3) (Itasaki et al., 1991), rhombencephalon (HH13) (Lumsden and Keynes, 1989; Martinez et al., 1995), and diencephalon (Puelles et al., 1987; Marin and Puelles, 1994), which demonstrated that regional plasticity is lost shortly before or after the onset of neurogenesis.

\section{Difference between E10.5 and E11.5 transplants}

The presence of calretinin neurons overlying the parietal cortex was used as a marker of parietal regionalization (Meyer et al., 1998) at early stages to investigate the marked difference in the growth of cortical transplants dissected at E10.5 or E11.5. The growth defect in E10.5 explants is not related to a failure in the production of early neuronal populations in vitro because we found that calretinin-positive neurons develop in E10.5 explants maintained in culture for $1 \mathrm{~d}$. The behavior of E10.5 transplants suggests that a switch in proliferation control that normally operates between E10.5 and E11.5 cannot take place in our in vitro conditions. The winged helix transcription factor BF-1 controls proliferation rate in the telencephalon (Xuan et al., 1995). Loss of BF-1 function first affects proliferation in the basal telencephalon between E9.5 and E10.5, resulting in a smaller size of the telencephalic vesicle. Proliferation in the cortical primordium is also altered but at a later stage, between E10.5 and E12.5 (Xuan et al., 1995). Thus BF-1 is a good candidate to participate in such a switch in the mode of proliferation of cortical cells. Normal proliferation seems to be needed for the production of $\mathrm{H}-2 \mathrm{Z} 1-$ expressing cells.

\section{Effect of transplant dissociation on $\mathrm{H}-2 \mathrm{Z} 1$ expression}

It has been demonstrated that the acquisition of a limbic cortexspecific phenotype depends on the presence of specific components of the extracellular matrix. TGF $\alpha$ in association with collagen type IV acts as a signal, active before the final cell cycle, and is capable of inducing the expression of a limbic phenotype (Ferri and Levitt, 1995; Eagleson et al., 1997). It is clear in this case that diffusible factors associated with specific components of the extracellular matrix are necessary to maintain regional identity during development. Our aim in using dissociation was to decrease the influence of parietal-specific interactions that could be involved in the maintenance of somatosensory identity in the graft and also allow better access to putative diffusible signals produced by the host cortex. Dissociation has profound effects on inductive interactions by modifying the range effect (Jones et al., 1996) and the availability (Godsave and Slack, 1989; Grunz and Tacke, 1989) of diffusible inductive factors. Because dissociation is also expected to loosen direct cell-cell interactions that are necessary for the maintenance of proliferation (Temple and Davis, 1994) and the formation of layer IV neurons, the dissociated cells were reaggregated before grafting. Scattered $\beta$-galactosidase-positive cells were detected in dissociated transplants, in most cases fewer than illustrated in Figure $4 D$. The blue cells in H-2Z1 aggregates lacked organization, although it has been shown that cortical neurons dissociated at later embryonic stages (E18) and cultured as reaggregates reassemble into cortical layers (DeLong, 1970; Garber et al., 1980). Dissociation did not result in an increased influence of environmental signals on $\mathrm{H}-2 \mathrm{Z} 1$ expression in the graft. This suggests that cell-cell and cell-matrix interactions rather than diff usible signals are involved in the maintenance of somatosensory identity.

\section{REFERENCES}

Abdel-Majid RM, Leong WL, Schalkwyk LC, Smallman DS, Wong ST, Storm DR, Fine A, Dobson MJ, Guernsey DL, Neumann PE (1998) Loss of adenylyl cyclase I activity disrupts patterning of mouse somatosensory cortex. Nat Genet 19:289-291.

Arimatsu Y, Miyamoto M, Nihonmatsu I, Hirata K, Uratani Y, Hatanaka Y, Takiguchi-Hayashi K (1992) Early regional specification for a molecular neuronal phenotype in the rat neocortex. Proc Natl Acad Sci USA 89:8879-8883.

Barbe MF, Levitt P (1991) The early commitment of fetal neurons to the limbic cortex. J Neurosci 11:519-533.

Bittman K, Owens DF, Kriegstein AR, LoTurco JJ (1997) Cell coupling and uncoupling in the ventricular zone of developing neocortex. J Neurosci 17:7037-7044.

Cases O, Seif I, Grimsby J, Gaspar P, Chen K, Pournin S, Muller U, Aguet M, Babinet C, Shih JC, De Maeyer E (1995) Aggressive behavior and altered amounts of brain serotonin and norepinephrine in mice lacking MAOA. Science 268:1763-1766.

Cases O, Vitalis T, Seif I, De Maeyer E, Sotelo C, Gaspar P (1996) Lack of barrels in the somatosensory cortex of monoamine oxidase A-deficient mice: role of a serotonin excess during the critical period. Neuron 16:297-307.

Cohen-Tannoudji M, Morello D, Babinet C (1992) Unexpected position-dependent expression of $\mathrm{H}-2$ and beta2-microglobulin/lacZ transgenes. Mol Reprod Dev 33:149-159.

Cohen-Tannoudji M, Babinet C, Wassef M (1994) Early determination of a mouse somatosensory marker. Nature 368:460-463.

Dawson DR, Killakey HP (1987) The organization and mutability of the forepaw and hindpaw representations in the somatosensory cortex of the neonatal rat. J Comp Neurol 256:246-256.

DeFelipe J (1993) Neocortical neuronal diversity: chemical heterogeneity revealed by colocalization studies of classic neurotransmitters, neu- 
ropeptides, calcium-binding proteins, and cell surface molecules. Cereb Cortex 3:273-289.

Dehay C, Giroud P, Berland M, Smart I, Kennedy H (1993) Modulation of the cell cycle contributes to the parcellation of the primate visual cortex. Nature 366:464-466.

DeLong GR (1970) Histogenesis of fetal mouse isocortex and hippocampus in reaggregating cell cultures. Dev Biol 22:563-583.

Eagleson KL, Lillien L, Chan AV, Levitt P (1997) Mechanisms specifying area fate in cortex include cell-cycle-dependent decisions and the capacity of progenitors to express phenotype memory. Development 124:1623-1630.

Erlander MG, Tillakaratne NJ, Feldblum S, Patel N, Tobin AJ (1991) Two genes encode distinct glutamate decarboxylases. Neuron 7:91-100.

Ferri RT, Levitt P (1995) Regulation of regional differences in the differentiation of cerebral cortical neurons by EGF family-matrix interactions. Development 121:1151-1160.

Fox K, Schlaggar BL, Glazewski S, O'Leary DD (1996) Glutamate receptor blockade at cortical synapses disrupts development of thalamocortical and columnar organization in somatosensory cortex. Proc Natl Acad Sci USA 93:5584-5589.

Friedrich G, Soriano P (1991) Promoter traps in embryonic stem cells: a genetic screen to identify and mutate developmental genes in mice. Genes Dev 5:1513-1523.

Garber BB, Huttenlocher PR, Larramendi LH (1980) Self-assembly of cortical plate cells in vitro within embryonic mouse cerebral aggregates. Golgi and electron microscopic analysis. Brain Res 201:255-278.

Gitton Y, Cohen-Tannoudji M, Wassef M (1999) Role of thalamic axons in the expression of $\mathrm{H}-2 \mathrm{Z} 1$, a mouse somatosensory cortex specific marker. Cereb Cortex, in press.

Godsave SF, Slack JM (1989) Clonal analysis of mesoderm induction in Xenopus laevis. Dev Biol 134:486-490.

Grunz H, Tacke L (1989) Neural differentiation of Xenopus laevis ectoderm takes place after disaggregation and delayed reaggregation without inducer. Cell Differ Dev 28:211-217.

Itasaki N, Ichijo H, Hama C, Matsuno T, Nakamura H (1991) Establishment of rostrocaudal polarity in tectal primordium: engrailed expression and subsequent tectal polarity. Development 113:1133-1144.

Jones CM, Armes N, Smith JC (1996) Signalling by TGF-beta family members: short-range effects of Xnr-2 and BMP-4 contrast with the long-range effects of activin. Curr Biol 6:1468-1475.

Levitt P (1984) A monoclonal antibody to limbic system neurons. Science 233:229-301.

Levitt P, Barbe MF, Eagleson KL (1997) Patterning and specification of the cerebral cortex. Annu Rev Neurosci 20:1-24.

Lumsden A, Keynes R (1989) Segmental patterns of neuronal development in the chick hindbrain. Nature 337:424-428.

Marin F, Puelles L (1994) Patterning of the embryonic avian midbrain after experimental inversions: a polarizing activity from the isthmus. Dev Biol 163:19-37.

Martinez S, Marin F, Nieto MA, Puelles L (1995) Induction of ectopic engrailed expression and fate change in avian rhombomeres: intersegmental boundaries as barriers. Mech Dev 51:289-303.
Meyer G, Soria JM, Martinez-Galan JR, Martin-Clemente B, Fairen A (1998) Different origins and developmental histories of transient neurons in the marginal zone of the fetal and neonatal rat cortex. J Comp Neurol 397:493-518.

Nothias F, Fishell G, Ruiz i Altaba A (1998) Cooperation of intrinsic and extrinsic signals in the elaboration of regional identity in the posterior cerebral cortex. Curr Biol 8:459-462.

O'Leary DD, Stanfield BB (1989) Selective elimination of axons extended by developing cortical neurons is dependent on regional locale: experiments utilizing fetal cortical transplants. J Neurosci 9:2230-2246.

Owens DF, Kriegstein AR (1998) Patterns of intracellular calcium fluctuation in precursor cells of the neocortical ventricular zone. J Neurosci 18:5374-5388.

Puelles L, Amat JA, Martinez-de-la-Torre M (1987) Segment-related, mosaic neurogenetic pattern in the forebrain and mesencephalon of early chick embryos. I. Topography of AChE-positive neuroblasts up to stage HH18. J Comp Neurol 266:247-268.

Polleux F, Dehay C, Moraillon B, Kennedy H (1997) Regulation of neuroblast cell-cycle kinetics plays a crucial role in the generation of unique features of neocortical areas. J Neurosci 17:7763-7783.

Rakic P, Suner I, Williams RW (1991) A novel cytoarchitectonic area induced experimentally within the primate visual cortex. Proc Natl Acad Sci USA 88:2083-2087.

Schlaggar BL, O'Leary DD (1991) Potential of visual cortex to develop an array of functional units unique to somatosensory cortex. Science 252:1556-1560.

Schlaggar BL, Fox K, O'Leary DD (1993) Postsynaptic control of plasticity in developing somatosensory cortex. Nature 364:623-626.

Stanfield BB, O'Leary DD, Fricks C (1982) Selective collateral elimination in early postnatal development restricts cortical distribution of rat pyramidal tract neurones. Nature 298:371-373.

Steindler DA, Cooper NG, Faissner A, Schachner M (1989) Boundaries defined by adhesion molecules during development of the cerebral cortex: the $\mathrm{J} 1 /$ tenascin glycoprotein in the mouse somatosensory cortical barrel field. Dev Biol 131:243-260.

Temple S, Davis AA (1994) Isolated rat cortical progenitor cells are maintained in division in vitro by membrane-associated factors. Development 120:999-1008.

Van der Loos H, Woolsey TA (1973) Somatosensory cortex: structural alterations following early injuries to sense organs. Science 179:395-398.

Wilkinson DG (1992) Whole mount in situ hybridization of vertebrate embryos. In: In situ hybridization: a practical approach (Wilkinson DG, ed), pp 75-83. Oxford: IRL.

Woolsey TA, Van der Loos H (1970) The structural organization of layer IV in the somatosensory region (SI) of mouse cerebral cortex. The description of a cortical field composed of discrete cytoarchitectonic units. Brain Res 17:205-242.

Xuan S, Baptista CA, Balas G, Tao W, Soares VC, Lai E (1995) Winged helix transcription factor BF-1 is essential for the development of the cerebral hemispheres. Neuron 14:1141-1152. 